\title{
ANÁLISE DO NÍVEL DE EDUCAÇÃO EM GESTÃO FINANCEIRA DOS FUNCIONÁRIOS DE UMA INSTITUIÇÃO DE ENSINO SUPERIOR
}

\section{ANALYSIS OF LEVEL OF EDUCATION IN FINANCIAL MANAGEMENT STAFF OF INSTITUTION OF HIGHER EDUCATION}

Marcio Roberto Piccoli

Universidade do Oeste de Santa Catarina - UNOESC e Universidade Regional de Blumenau - FURB $\underline{\text { marcio.piccoli@unoesc.edu.br }}$

Tarcisio Pedro da Silva Universidade Regional de Blumenau - FURB tarcisio@furb.br

Submissão: 01/05/2014

Aprovação: 25/09/2015 


\title{
RESUMO
}

Este estudo objetivou identificar o nível de educação em gestão financeira dos funcionários de uma instituição de ensino do Meio Oeste de Santa Catarina. A pesquisa é do tipo descritiva desenvolvida a partir de um questionário estruturado, segregado em dois blocos: o primeiro bloco aborda questões a fim de caracterizar o perfil sócio econômico dos respondentes, e o segundo busca identificar o nível de educação financeira e gestão financeira pessoal; enviado à uma população de 273 funcionários, dos quais foram respondidos 103 questionários. Os resultados apontam que os agentes sociais da pesquisa estão agrupados em uma faixa etária entre 21 e 40 anos, sendo representada por $83 \%$ dos respondentes, a maioria do gênero feminino (76\%) com estado civil casado/união estável (51\%). A investigação permitiu identificar um conhecimento, na educação financeira, sobre o tema liquidez e o efeito dos juros, com utilização de algum tipo de planejamento e/ou controle financeiro, responsável pelo baixo índice de endividamento e administração dos recursos.

Palavras Chave: Educação Financeira. Finanças Pessoais. Planejamento Financeiro.

\begin{abstract}
This study aimed to identify the level of education in financial management of the staff of an educational institution in the Midwest of Santa Catarina. The research is descriptive, developed from a structured questionnaire, grouped into two blocks: the first block addresses issues in order to characterize the profile economic partner of respondents, and the second is to identify the level of education in personal financial management; sent to a population of 273 employees, of which 103 questionnaires were answered. The results show that the social agents of the survey are grouped in an age group between 21 and 40 years and is represented by $83 \%$ of respondents, the majority of women $(76 \%)$, and $51 \%$ married or common-law marriage. The investigation identified a knowledge, financial education on the subject of liquidity and the effect of interest, using some sort of planning and / or financial control, responsible for the low debt ratio and administration of resources.
\end{abstract}

Keywords: Financial Education. Personal Finance. Financial Planning. 


\section{INTRODUÇÃO}

Para Mankiw (1999, p. 532) o investimento em educação, ou capital humano, é "tão importante quanto o investimento em capital físico para o sucesso econômico de longo-prazo de um país". Para o autor, "uma das maneiras pelas quais a politica do governo pode melhorar o padrão de vida é proporcionando um bom ensino e o incentivo a seu uso pela população".

Pinheiro (2008) destaca que as pessoas estão diariamente realizando atividades relacionadas aos seus recursos financeiros, como abrir conta bancária, contratar seguros, comprar ações, planejar o orçamento familiar, adquirindo planos de previdência, financiando sua casa própria ou simplesmente pagando contas com cartão de crédito no vencimento.

Para Claudino, Nunes e Da Silva (2009) os indivíduos precisam dominar um amplo conjunto de informações, destacando-se a importância da educação financeira, que compreende a inteligência de ler e interpretar números e assim transformá-los em informação para elaborar um planejamento financeiro que garanta um consumo saudável e o futuro equilibrado nas finanças pessoais.

Considerando a necessidade de investimento constante, na temática que envolve a educação financeira, que considera o consumo de recursos em função das necessidades dos indivíduos, considerado instrumento de gestão financeiro de pessoas e organizações, nessa incursão, em que há a necessidade da adequada gestão dos recursos, o estudo apresenta como problema de pesquisa: qual o nível de educação e gestão financeira dos funcionários de uma instituição de ensino superior do Meio Oeste Catarinenses? Dessa forma, a fim de responder o problema de pesquisa, o objetivo do estudo é analisar nível de educação e gestão financeira dos funcionários de uma instituição de ensino superior do Meio Oeste Catarinense.

Como fatores motivadores que justificam esta pesquisa, apresenta-se algumas ponderações, que se destaca a educação financeira, como apresentada por Sousa e Torralvo (2003) e Vieira et al. (2009) que a educação financeira ainda é incipiente no Brasil precisando ser mais explorada por pesquisas acadêmicas e científicas, contribuindo para ampliação do conhecimento na área. Para Lucci et al. (2006) é necessário se ter uma conscientização em que, auxiliada pela educação financeira, a população consiga decidir sobre as variáveis envolvidas a fim de se ter uma decisão financeira eficiente.

Em estudos realizados por Claudino, Nunes e Silva (2009) a educação dos respondentes demonstrou-se insipiente nas áreas de liquidez de aplicações e planejamento financeiro, sendo necessária a implantação de cursos de gestão financeira. Nessa perspectiva 
de melhora das finanças pessoais, a experiência financeira está diretamente relacionada com o sucesso do planejamento (LUSARDI; MITCHELL, 2011).

O endividamento das pessoas pode ser explicado a partir das variáveis como: sexo, etnia, educação, história familiar, renda, número de cartões de crédito, utilização do cartão de crédito e de títulos de dívida, bem como variáveis psicológicas, como: locus de controle, autoestima e valores (LUNT; LIVINGSTONE, 1991), idade, ocupação, circunstâncias econômicas, personalidade, estilo de vida e valores, bem como transações decorrentes da vida como casamento, nascimento de filhos, divórcio e viuvez (KLOTER; KELLER, 2006).

Ainda que tenhamos pesquisas sobre a educação financeira, está distante de ser um tema recorrente na literatura acadêmica, em que percebe-se uma escassez de estudos investigando a educação financeira pessoal e por ser um ambiente com diferentes níveis de escolaridade, espera-se contribuir com o tema educação financeira e planejamento financeiro ampliando a discussão sobre o tema o qual se considera de fundamental importância para a qualidade de vida dos indivíduos.

O estudo justifica-se ainda pela importância em planejar-se financeiramente para o futuro, a partir de decisões tomadas no presente. Nesse sentido, se faz necessário possuir conhecimento sobre gestão e planejamento financeiro, em que Lusardi e Mitchell (2011) afirmam que a cultura e de educação financeira são fundamentais, em que ambas são importantes para o bem estar da vida das pessoas.

\section{REFERENCIAL TEÓRICO}

\subsection{Finanças Comportamentais}

Financiamentos e investimentos são decisões que o indivíduo faz, consideradas as situações de risco. Os primeiros estudos sobre o comportamento humano foram realizados por Kahnemann e Tversky (1974, 1979), os quais consideraram que o comportamento do indivíduo varia de acordo com o ambiente econômico, ou seja, os indivíduos têm mais propensão a ser avesso ao risco quando confrontados à ambientes positivos e mais adeptos a riscos quando o ambiente lhe é negativo, contrariando a lógica racional do ser humano.

Kahnemann e Tversky (1974) identificaram que o ser humano possui vieses mentais para a tomada de decisões, ou seja, dada a complexidade na tomada de decisões, o indivíduo tem sua capacidade de decisões limitada. Esse viés mental é denominado de heurística, ou seja, são atalhos mentais que podem facilitar ou dificultar o processo de tomada de decisões. 
Para Macedo (2003) a heurística é entendida como um conjunto de regras que é utilizado a partir de uma metodologia e tem como finalidade a resolução de problemas que, apesar de não rigorosos, possibilitam obter uma solução satisfatória.

Após estudos de 1974, Kahnemann e Tversky (1979) denominaram o estudo do comportamento humano de Teoria do Prospecto, ou seja, há a influência do efeito certeza, em que esse efeito contribui para uma aversão ao risco quando envolve certeza de ganhos e se está mais propenso a riscos quando há certezas de perdas. Nesse sentido, o comportamento financeiro do indivíduo muitas vezes é influenciado pela falta de racionalidade em tomar decisões, a qual é determinante no favorecimento de um erro de decisão (LUCENA; FERNANDES; SILVA, 2011). Para Tennyson e Nguyen (2001) os indivíduos se comportam de forma irracional quando se deparam com fenômenos financeiros. Para os autores apesar de se ter conhecimento sobre finanças, as decisões são tomadas sem uma racionalidade e por esse motivo suas decisões não os satisfazem.

As finanças comportamentais buscam compreender as decisões tomadas pelos indivíduos de forma irracional, e que a partir disso se cria barreiras cognitivas fazendo com que ocorram erros sistemáticos de avaliação de valores, probabilidades e riscos (ROGERS, FAVATO E SECURATO, 2007).

Nesse contexto de estudos do comportamento financeiro, diversos são os itens que influenciam os indivíduos na tomada de decisões que na opinião de Assunção (2011), não são estritamente racionais, como atitudes, motivos, interesses, experiência entre outros (ASSUNÇÃO, 2011). Para o autor, aspectos comportamentais fazem parte da vida do ser humano, tendo em vista esse ser um animal sociável.

Em finanças comportamentais está praticamente comprovado que o ser humano não age somente de forma racional. Suas decisões possuem um viés psicológico em que se avaliam os resultados a partir das decisões de perda, ganho, retorno, fracasso, excesso de confiança, sendo estes itens capazes de induzir às escolhas (LUCENA; FERNANDES; DA SILVA, 2011).

Para Halfed e Torres (2001) e Lima (2003) a autoconfiança é uma característica de comportamento presente na grande maioria da população, em que diversos estudos comprovam que $80 \%$ das pessoas se consideram acima da média no que diz respeito a suas habilidades. A autoconfiança excessiva faz com que se acredite que as informações sejam melhores e mais confiáveis do que a dos outros e por consequência as decisões são mais arriscadas que os outros (LIMA, 2003); o que pode levar a uma decisão errônea (KIMURA; BASSO, 2003). Alguns estudos sobre comportamento financeiro já têm sido realizados, mas 
de forma ainda reduzina no ambiente acadêmico. Nesse sentido, citamos os de Carducci e Wong (1998), Barber e Odean (2002), Favato e Securato (2007), Serra et al. (2010), Lucena, Fernandes e Da Silva (2011) e Pimenta, Borsato e Ribeiro (2012).

A partir dos estudos citados, percebe-se que principalmente as decisões entre comprar ou investir, assim como o planejamento financeiro, possuem forte ligação com os objetivos de finanças comportamentais identificados por Carducci e Wong (1998), e Rogers, Favato e Securato (2007) estando ainda diretamente relacionado com decisões de vieses psicológicos, identificados por Barber e Odean (2002) e Lucena e Fernandes Da Silva (2011).

\subsection{Educação Financeira}

A tomada de decisão se faz com conhecimento adequado e aprofundado do assunto, o qual requer estudo e dedicação. Em finanças, frequentemente o gestor lida com decisões de curto ou de longo prazo para as quais precisa ter formação e habilidades para escolher das opções analisadas a alternativa que projete os melhores benefícios (GITMAN, 1997).

Em pesquisas realizadas por Chen e Volpe $(1998,2002)$ a falta de educação financeira pessoal em estudantes universitários limita a capacidade de tomar decisões tanto individuais quanto empresariais. Para os autores, estudantes com maior grau de educação financeira estão mais propensos a acertos quando deparados com decisões de investimentos. A pesquisa mostrou que estudantes menos experientes tendem a ter opiniões erradas e tomar decisões incorretas.

O nível de educação financeira pode ser medido pelos conhecimentos básicos de liquidez de ativos, valor do dinheiro no tempo, efeito da incidência de juros compostos, custo de financiamento, fluxo de caixa, orçamento e risco (LUCCI et al. 2006). Existe diferença entre poupar e investir, ou seja, enquanto o primeiro se abdica de algo a consumir no presente, o segundo está com um olhar no futuro, abrangendo um conceito muito mais amplo que é o de ser remunerado a fim de atingir um montante desejado no futuro (CLAUDINO; NUNES; SILVA, 2009).

Pessoas mais experientes são mais propensas a planejar e terem sucesso no uso dos recursos financeiros, confiando em métodos formais como seminários, palestras e especialistas em finanças ao invés da família e colegas de trabalho. Nesse sentido Lusardi e Mitchell (2011) argumentam que são necessários esforços direcionados a educação financeira.

No Brasil a educação financeira ainda precisa ser mais abordada, visto que o tema não faz parte do currículo das escolas, apenas com algumas ações isoladas nos currículos 
escolares complementares (SAVOIA; SAITO; SANTANA, 2007), que aguarda inclusão no curriculum escolar conforme Projeto de Lei no 171/2009.

Algumas atividades isoladas são executadas por órgãos públicos ou privados em relação à educação financeira. Conforme destacado por Savoia, Saito e Santana (2007) organizações como Banco Central do Brasil (BACEN), Comissão de Valores Mobiliários (CVM), Bolsa de Valores de São Paulo (Bovespa) desenvolvem algum programa de educação financeira. Por outro lado, os autores indicam que o Ministério da Educação (MEC) e Universidades não possuem um programa ou processo de educação financeira em seus currículos escolares.

Nos Estados Unidos, de acordo com Bernheim, Garret e Maki (1997) até o ano de 1985, 29 dos 50 estados americanos, ou seja, quase 60\% já haviam incluído a Educação Financeira como conteúdo obrigatório nas escolas secundárias, e 14 estados já possuíam em seu currículo escolar o estudo sobre finanças pessoais.

Para que se tenha uma evolução sadia de educação financeira, o inicio se dá quando criança. Nesse sentido, Pinheiro (2008) afirma que a educação financeira pode ajudar as crianças a compreenderem o valor do dinheiro ensinando-as a gerir orçamentos e poupar. Manton et al. (2006), afirmam, que universidades poderiam suprir a necessidade de conhecimento sobre finanças. Seus estudos concluíram que o ensino médio não consegue educar os alunos de forma substancial em relação a conceitos de finanças, cabendo ao ensino superior à inclusão do tema educação financeira pessoal nas suas atividades.

A educação financeira iniciada na escola, também deve ser implementada nas empresas. Para Dolvin e Templeton (2006) o incentivo das empresas pela educação financeira, melhora a compreensão dos empregados por uma melhor diversificação de investimentos. Para os autores, a participação em seminários faz com que os empregados se tornem mais conservadores em suas decisões de investimentos, sendo coerente e tolerante aos riscos.

Quanto maior a educação financeira, melhor a administração e gerenciamento dos recursos. Para Frankenberg (1999), Lucci et al.(2006), Zerrenner (2007) e Lizote, Simas e Lana (2012) a importância da educação financeira pode ser vista sob a perspectiva de satisfação pessoal na qual jovens e adultos a partir de suas decisões comprometem seu futuro, tendo como consequências a desorganização de suas contas, a inclusão de seus nomes em sistemas de proteção ao crédito, podendo atrasar o futuro profissional. A segunda perspectiva, de consequências mais graves, é a do bem estar da sociedade, ou seja, pode culminar em uma sobrecarga dos já precários sistemas públicos, ocasionando politicas públicas de correção. 
Ainda nesse contexto, Worthigton (2008) afirma que o conhecimento financeiro pode ser dividido em pessoal e profissional, em que o pessoal está relacionado a conhecimentos econômicos, orçamentários, poupar e investir, foco do estudo; e o conhecimento profissional compreende o entendimento de demonstrações financeiras, fluxos de caixa e mecanismos de governança empresarial.

\subsection{Planejamento Financeiro Pessoal}

Para Gitman (1997) finanças podem ser definidas como a arte e a ciência da gestão do dinheiro. Nesse contexto de gestão e administração, o planejamento é instrumento indispensável para melhor otimização dos recursos. A administração financeira precisa estar aliada a contabilidade e a economia, em que a primeira está relacionada com informações financeiras de tomada de decisão sobre investimentos e financiamentos, bem como a análise e planejamento financeiro e a segunda, está relacionada com o ambiente e as técnicas de decisão a serem tomadas (GITMAN, 1997).

O planejamento é o inicio das ações a serem realizadas a fim atingir as metas definidas. Para Ross, Westerfield e Jaffe (2002, p. 589) “o planejamento financeiro estabelece o método pelo qual as metas financeiras devem ser atingidas", em que o plano financeiro significa que está declarado o que deve ser feito num período futuro, a partir de decisões que envolvem períodos longos de implantação. Planejamento financeiro pessoal significa o estabelecimento e o seguimento de uma estratégia que tem por objetivo a acumulação de bens e valores que formarão o patrimônio pessoal ou de um conjunto de pessoas, podendo ser dimensionado para um período de curto, médio ou de longo prazo (FRANKENBERG 1999).

Para Camargo (2007) a primeira etapa do processo de planejamento financeiro envolve um plano personalizado que ajuda a estimar as obrigações atuais e a posição financeira do indivíduo, clarificar metas e objetivos e dirigir um curso de ação para um futuro financeiro mais seguro. Para o autor, metas individuais podem variar dependendo do tamanho da família, estilo de vida e interesses, podendo ser identificadas no curto ou no longo prazo.

Nesse viés de metas e objetivos, têm-se as decisões de consumo, que na concepção de Vitt (2004) são afetadas por aspectos psicológicos, físicos e sociais enraizados em sentimentos e emoções. Para Pinheiro (2008) a diversificação de produtos para tomada de decisões trazem vários benefícios, por outro lado o nível de conhecimento necessário compreender toda essa diversidade ficou além do entendimento que se detém. Para o autor, o desconhecimento financeiro pode submeter uma pessoa desinformada a dívidas excessivas. 
A educação financeira pode auxiliar no problema do endividamento a partir do conhecimento dos instrumentos de tomada de decisões após o reconhecimento das razões que levam ao endividamento. As principais razões do endividamento podem ser atribuídas a incidentes pessoais/familiares, consumismo e falta de controle (falta de planejamento e má administração do dinheiro) (ZERRENNER 2007).

Na percepção de Pinheiro (2008), se de um lado as pessoas sentem a necessidade de um planejamento para administrar suas finanças pessoais, para redução do elevado nível de endividamento, por outro falta educação financeira com visão para os investimentos. A escassez de educação financeira é um dos fatores que explica os baixos índices de poupança no Brasil. A compra de um carro ou imóvel, por exemplo, são mais atrativos do que uma capitalização de recursos ou previdência privada os quais podem levar 30 anos para colher os resultados (PINHEIRO, 2008). Nesse viés de pensamento, o imediatismo é mais importante do que a visão de longo prazo.

Nesse contexto, Navarro (2009, p.151) contribui afirmando que a lógica da educação financeira é a de que "antes de pensar em investir é extremamente necessário saber o porquê de investir, ou seja, a necessidade de estabelecimento de objetivos e de metas claras deve ser estabelecida fim de que não se caia em alguma moda consumista, prejudicando o atingimento dos objetivos traçados".

As abordagens apresentadas destacam que a educação financeira desempenha papel fundamental no processo de administração do dinheiro, fazendo com que os indivíduos tenham condições de melhor planejarem suas finanças, garantindo assim no presente e futuro uma melhor qualidade de vida, ou se preferirem cair nas tentações da diversidade de produtos e serviços hoje oferecidos.

\section{PROCEDIMENTOS METODOLÓGICOS}

Considerando os objetivos propostos, esta pesquisa pode ser caracterizada como descritiva, pois tem como principal objetivo descrever o nível de gestão e de educação financeira dos funcionários de uma instituição de ensino superior, tendo como procedimento técnico a levantamento de dados a partir de um questionário (survey).

Para Collis e Hussey (2005, p.25) "descritiva é a pesquisa utilizada para descrever o comportamento dos fenômenos e é usada para identificação e obtenção de informações sobre características de um determinado problema em que os dados compilados a partir de uma 
pesquisa descritiva, costumam ser quantitativos utilizando técnicas estatísticas para resumir as informações encontradas".

A pesquisa foi realizada a partir da aplicação de um questionário estruturado composto por 22 questões enviadas via google docs para uma população de 273 funcionários de uma instituição de ensino superior do Meio Oeste de Catarinense, tendo obtido um retorno de 103 questionários. Trata-se de uma amostra intencional e de acessibilidade aos agentes sociais desta instituição de ensino. O questionário foi dividido em dois blocos: o primeiro aborda questões a fim de caracterizar o perfil sócio econômico dos respondentes, com perguntas relacionadas a idade, gênero, estado civil, renda pessoal e familiar, grau de escolaridade, indicativo de empréstimos e informações de gastos e o segundo busca identificar o nível de educação e de gestão financeira dos respondentes.

Quanto a análise dos dados, as respostas foram tabuladas em planilhas do excel e analisadas utilizando-se da estatística descritiva, comparando-as com resultados de pesquisas anteriores.

\section{ANÁLISE DOS RESULTADOS}

O perfil sócio econômico dos respondentes é analisado a partir das Tabelas 01 a 03, sendo a Tabela 1 a análise dos dados obtidos no que se refere à renda líquida pessoal do respondente e a renda líquida de seu grupo familiar.

Tabela 01: Renda Líquida

\begin{tabular}{|c|c|c|c|c|c|}
\hline \multicolumn{3}{|c|}{ Renda Líquida Pessoal } & \multicolumn{3}{|c|}{ Renda Líquida Familiar } \\
\hline Faixa Receita Líquida & Freq. & $\%$ & Faixa Receita Líquida & Freq. & $\%$ \\
\hline Até R\$ $1.000,00$ & 10 & 10 & Até R\$1.000,00 & 2 & 2 \\
\hline $\mathrm{R} \$ 1.000,01$ até $\mathrm{R} \$ 1.500,00$ & 32 & 31 & $\mathrm{R} \$ 1.000,01$ até $\mathrm{R} \$ 2.000,00$ & 12 & 12 \\
\hline $\mathrm{R} \$ 1.500,01$ até $\mathrm{R} \$ 2.000,00$ & 24 & 23 & $\mathrm{R} \$ 2.000,01$ até $\mathrm{R} \$ 3.000,00$ & 16 & 16 \\
\hline $\mathrm{R} \$ 2.000,01$ até $\mathrm{R} \$ 2.500,00$ & 14 & 14 & $\mathrm{R} \$ 3.000,01$ até $\mathrm{R} \$ 4.000,00$ & 24 & 23 \\
\hline \multirow[t]{2}{*}{ Acima de $\mathrm{R} \$ 2.500,00$} & 23 & 22 & $\mathrm{R} \$ 4.000,01$ até $\mathrm{R} \$ 5.000,00$ & 23 & 22 \\
\hline & & & Acima de $\mathrm{R} \$ 5.000,01$ & 26 & 25 \\
\hline Totais & 103 & 100 & & 103 & 100 \\
\hline \multicolumn{6}{|l|}{ Legenda: } \\
\hline Freq.: Quantidade de responde & & & & & \\
\hline
\end{tabular}

O perfil econômico dos respondentes, com base na Tabela 01- Renda Líquida identifica que a maioria dos respondentes possui renda entre $R \$ 1.000,01$ e $R \$ 2.000,00$, representado por $54 \%$, ou seja, 56 entrevistados. Por outro lado, $10 \%$ possuem renda de até R \$ 1.000,00, mensais. Ao analisar a renda líquida mensal da família, o estudo mostra que a 
maior concentração está nos rendimentos líquidos acima de $\mathrm{R} \$ 5.000,00$, representando 1/4 dos entrevistados e que apenas $2 \%$ possuem renda familiar de até $\mathrm{R} \$ 1.000,00$.

A partir da Tabela 02 - Tipos de Dívida analisa-se os tipos de dívida dos respondentes e sua identificação com o planejamento financeiro.

\section{Tabela 02: Tipos de dívida}

\begin{tabular}{|c|c|c|}
\hline Alternativas & Freq. & $\%$ \\
\hline $\begin{array}{l}\text { a) Sim, tenho, mas trata-se de financiamento de longo prazo, cuja prestação eu sempre procuro } \\
\text { pagar em dia. }\end{array}$ & 29 & 28 \\
\hline b) Sim, tenho, mas não sei bem quando nem como irei pagá-las. & 2 & 2 \\
\hline $\begin{array}{l}\text { c) Sim, mas vou pagá-las em pouco tempo, já que tomei o cuidado de calcular na ponta do } \\
\text { lápis como e quando iria quitá-las. }\end{array}$ & 27 & 26 \\
\hline $\begin{array}{l}\text { d) Não, não tenho dívidas pessoais. Sempre faço o planejamento necessário para comprar à } \\
\text { vista e com desconto. }\end{array}$ & 45 & 44 \\
\hline Totais & 103 & 100 \\
\hline \multicolumn{3}{|l|}{ Legenda: } \\
\hline Freq.: Quantidade de respondentes & & \\
\hline
\end{tabular}

A partir da Tabela 02 - Tipos de Dívida, - 28\% dos respondentes possuem dívidas de financiamento de longo prazo, acima de 2 anos, procurando sempre pagar as prestações em dia; $26 \%$ com dívidas a serem pagas em pouco tempo após o vencimento e $2 \%$ estão endividados sem saber quando e como irá quitá-las. A maioria dos respondentes (44\%) não possuem dívidas pessoais, indicando que realizam algum tipo de planejamento para compras a vista e com desconto.

Analisando os dados referente à escolaridade dos respondentes, em que a maioria dos respondentes possui uma especialização/MBA (42\%), seguido de $28 \%$ com ensino superior completo e $17 \%$ com superior incompleto, representando $87 \%$ ou 89 entrevistados, percebe-se que pelos estudos de Vieira et al. (2009) e Lusardi e Mitchell (2011), a escolaridade, e a experiência tem relação direta com a aplicação do dinheiro, assim como a idade pode influenciar na percepção de realização de dívidas, em que observou-se que $54 \%$ dos respondentes possuem idade entre 21 e 30 anos e $43 \%$ com idade superior a 31 anos.

A Tabela 03 buscou identificar os principais gastos realizados pelos respondentes, desde moradia, alimentação e transporte a lazer e outros, referente ao seu rendimento líquido mensal. 
Tabela 03: Proporção de Gastos

\begin{tabular}{lcc}
\hline Gastos & $\begin{array}{c}\text { Média } \\
(\boldsymbol{\%})\end{array}$ & $\begin{array}{c}\text { Máximo } \\
(\boldsymbol{\%})\end{array}$ \\
\hline Moradia (Aluguel, casa própria-financiamento- condomínio, agua, energia-telefone-IPTU) & 15 & 60 \\
\hline Alimentação (supermercado-restaurante-padaria) & 17 & 60 \\
\hline Transporte (coletivo ou combustível-seguros-impostos) & 7 & 40 \\
\hline Saúde (planos de saúde-odontológicos-seguros) & 4 & 30 \\
\hline Poupança e Investimento (planos de aposentadoria-aplicações financeiras) & 9 & 40 \\
\hline Educação (mensalidades- aulas de reforço-transporte -cursos de idiomas) & 11 & 30 \\
\hline Vestuário e higiene (roupas-academia-estética) & 11 & 50 \\
\hline Financiamento e prestações para aquisição de bens & 9 & 50 \\
\hline Lazer e outros (livros - revistas -teatros-viagens-confraternizações-presentes-internet-TV) & 8 & 30 \\
\hline Outros. & 7 & 30
\end{tabular}

Fonte: Dados da pesquisa.

Percebe-se pela Tabela 03, que em relação à renda líquida mensal dos respondentes, a maior destinação dos recursos está sendo para moradia e alimentação, as quais juntas somam $32 \%$, ou seja, praticamente um terço da renda é destinado para esses dois gastos. Por outro lado, o percentual máximo apresentado foi de $60 \%$ respectivamente, indicando que há respondentes comprometendo $60 \%$ de seus rendimentos com gastos de moradia e alimentação. Os menores percentuais de gastos são em ordem crescente, saúde (4\%), transporte e outros $(7 \%)$, lazer ( $8 \%)$, poupança e financiamentos $(9 \%)$, e educação e vestuário com $11 \%$ cada.

Semelhante ao estudo IBGE (2008-2009) o qual apontou que os maiores gastos das famílias brasileiras são com moradia e alimentação, com 35,9\% e 19,8\% respectivamente, tendo como gastos mais baixos os de educação (3\%), vestuário $(5,5 \%)$.

O primeiro bloco de perguntas nos mostra em relação ao perfil dos respondentes, que a idade, a escolaridade tem influência da gestão dos recursos financeiros, haja vista, que a maioria dos respondentes possui cursos de especialização e apresentam-se com média acima de 31 anos de idade. Por se tratar de uma instituição de ensino, justifica-se a maioria dos respondentes possuir escolaridade com algum tipo de especialização/MBA, bem como não possuírem dívidas, procurando planejar-se e efetuar pagamentos a vista com descontos.

O segundo bloco da pesquisa busca investigar qual o nível de educação e de gestão financeira, dos respondentes a partir da análise dos dados da Tabela 04 a 06 (Educação Financeira) e da Tabela 07 a 10 (Gestão Financeira). A pergunta identificada na Tabela 04 Conhecimentos sobre Gerenciamento do Dinheiro, busca identificar o conhecimento em gerenciar os recursos financeiros partindo de nada seguro a muito seguro. 
Tabela 04: Conhecimentos sobre Gerenciamento do Dinheiro

\begin{tabular}{lcc}
\hline & Freq. & \% \\
\hline Nada seguro - Eu gostaria de possuir um nível muito melhor de educação financeira & 3 & 3 \\
\hline Não muito seguro - Eu gostaria de saber um pouco mais sobre finanças & 35 & 34 \\
\hline $\begin{array}{l}\text { Razoavelmente seguro - Eu conheço a maioria das coisas que eu precisaria saber sobre o } \\
\text { assunto. }\end{array}$ & 59 & 57 \\
\hline Muito seguro - Eu possuo conhecimentos bastante amplos sobre finanças. & 6 & 6 \\
\hline Totais & $\mathbf{1 0 3}$ & $\mathbf{1 0 0}$ \\
\hline Legenda: & \\
\hline Freq.: Quantidade de respondentes &
\end{tabular}

Fonte: Dados da pesquisa.

Conforme dados da Tabela 04 - Conhecimentos sobre Gerenciamento do Dinheiro percebe-se que $57 \%$ dos funcionários se sentem razoavelmente seguros, ou seja, conhecem a maioria das coisas que precisa sobre o assunto. Por outro lado, $34 \%$ não se sentem muito seguro e gostariam de saber um pouco mais sobre finanças. Apenas $6 \%$ dos respondentes se consideram muito seguro e com amplo conhecimento de finanças, demonstrando que a teoria abordada e a partir de estudos anteriores que educação financeira é essencial para o gerenciamento do dinheiro (SAVOIA; SAITO; SANTANA, 2007, CLAUDINO; NUNES; DA SILVA, 2009 e LIZOTE; SIMAS; LANA, 2012).

Lucci et al. (2006) aplicando uma pesquisa com alunos de graduação em administração e ciências contábeis, encontrou um percentual de $42 \%$ para razoavelmente seguras e 54\% para pessoas não muito seguras, ou seja, o oposto dos achados nesta pesquisa. Tal diferença pode ser justificada pela população em que foi aplicada a pesquisa, ou seja, alunos de graduação ainda com um baixo conhecimento de finanças e com idade abaixo de 30 anos.

A partir da Tabela 05 - Fonte de Educação Financeira apresenta-se os dados referentes à formação do conhecimento financeiro, ou seja, qual a forma ou fonte utilizada para satisfazer as deficiências de educação financeira, afim de melhor auxiliar na gestão de seus recursos.

Tabela 05: Fonte de educação financeira

\begin{tabular}{lcc}
\hline Fonte de maior aquisição de conhecimento financeiro & Freq. & \% \\
\hline Em casa com a família & 33 & 32 \\
\hline De conversas com amigos & 0 & 0 \\
\hline No trabalho & 9 & 9 \\
\hline Em aulas escola/faculdade & 19 & 18 \\
\hline De revistas, livros, TV e o rádio & 7 & 7 \\
\hline De minha experiência prática. & 35 & 34 \\
\hline
\end{tabular}




\begin{tabular}{lcc} 
Melhor fonte de informação financeira & Freq. & $\mathbf{\%}$ \\
\hline Palestras inseridas em eventos (instruções, seminários de aperfeiçoamento profissional, etc.) & 33 & 32 \\
\hline Cursos de curta duração (um dia ou menos). & 40 & 39 \\
\hline Serviço de assessoria financeira via convênios com universidades e escolas. & 22 & 21 \\
\hline Cursos de longa duração (mais de uma semana). & 8 & 8 \\
\hline Total & $\mathbf{1 0 3}$ & $\mathbf{1 0 0}$
\end{tabular}

Legenda:

Freq.: Quantidade de respondentes

Fonte: Dados da pesquisa.

Percebe-se pela Tabela 05 - Fonte de educação financeira, que 34\% dos respondentes consideram a experiência prática a forma de maior aquisição de conhecimentos financeiros, seguido dos ensinamentos oriundos da família (32\%). Os dados aqui apresentados, possuem relação com as pesquisas de Vieira et al. (2009) os quais afirmam que a educação financeira faz parte do cotidiano das pessoas; e semelhante a pesquisa de Pinheiro (2008) o qual afirma que a educação deve ter início quando criança e que, quando jovens, evitarão de cair em armadilhas financeiras.

Semelhante ao estudo de Lusardi e Mitchell (2011) os quais identificaram que o uso de calculadora/planilha $(37,8 \%)$ e a participação em seminários $(35,3 \%)$ são as principais fontes de aprendizado financeiro, assemelhando-se ao estudo quando relacionado com a experiência prática. Nota-se que os respondentes têm o trabalho como uma baixa fonte de conhecimento financeiro (9\%) e que por outro lado não buscam nenhum conhecimento com amigos $(0 \%)$.

A Tabela 05 apresenta ainda que a maioria dos os respondentes $(71 \%)$ considera, como melhor fonte de informação financeira cursos de curta duração (39\%) e palestras inseridas em eventos (32\%). Em terceiro lugar os serviços de assessoria financeira foram lembrados por $21 \%$ dos respondentes, seguido de $8 \%$ dos cursos de longa duração. Nesse sentido, como a educação financeira é originada da experiência prática, seguido de boas ações praticadas em família, cursos de curta duração parece satisfazer as necessidades dos respondentes, os quais não necessitam de cursos com mais de uma semana de duração.

A Tabela 06 - Formas de Financiamento das Dívidas buscou identificar nos respondentes qual a forma mais utilizada para financiarem de suas dívidas, a fim de observar se o respondente possui conhecimento sobre o custo financeiro do dinheiro e sua melhor forma de utilização. 
Tabela 06: Formas de financiamento das dívidas

\begin{tabular}{lcc}
\hline Renda da Família & 50 & 49 \\
\hline Cheque Especial & 0 & 0 \\
\hline Financiamento Bancário & 10 & 10 \\
\hline Financiamento em Cooperativa de Crédito & 4 & 4 \\
\hline Crediário & 11 & 11 \\
\hline Crédito Pessoal/Consignados & 8 & 8 \\
\hline Cartão de Crédito & 20 & 19 \\
\hline Total & $\mathbf{1 0 3}$ & $\mathbf{1 0 0}$ \\
\hline Legenda: & &
\end{tabular}

Fonte: Dados da pesquisa.

Percebe-se pela Tabela 06 que para 49\% dos respondentes a renda familiar é a forma mais utilizada de financiamento, seguido de $19 \%$ e $10 \%$ de cartão de crédito e financiamento bancário respectivamente. Confrontando esses dados com os da Tabela 04, em que os respondentes se consideram razoavelmente seguros quando ao conhecimento financeiro, temse que ainda os respondentes preferem o cartão de crédito como segunda opção de financiamento de seus gastos. A Tabela 06 mostra ainda que $8 \%$ utiliza o crédito consignado, $4 \%$ cooperativas de crédito e nenhum dos respondentes utiliza o limite do cheque especial como mecanismo de financiamento de seus gastos.

Claudino, Nunes e Silva (2009) identificaram que 40,5\% dos pesquisados não utilizam cheque especial, 58,3\% tem conhecimento de juros e despesas financeiras e 95,5\% usam adequadamente o cartão de crédito. Os autores encontraram em sua pesquisa que a partir de algumas variáveis, a exemplo das citadas, $44 \%$ dos servidores pesquisados possuem conhecimento insuficiente sobre educação financeira, com um nível entre 0 e $60 \%$.

Quanto ao conhecimento dos respondentes sobre a o uso do cartão de crédito, a essa foi respondida corretamente por $71 \%$ dos pesquisados, ou seja, os respondentes entendem que o pagamento mínimo no cartão faz aumentar as despesas, considerando os juros (custo) da utilização desse recurso financeiro. Lucci et al. (2006) identificou que (77\% a 87\%), quanto maior o nível de instrução, maior foi o acerto dessa questão, encontrando um percentual de 87,5\% de acerto para os alunos que cursaram 3 disciplinas na graduação.

Sobre a educação financeira, percebeu-se que o conhecimento dos respondentes referente a dívidas e custos financeiros, correspondeu a $63 \%$, de acerto, semelhante ao encontrado por Vieira et al. (2009), (72,6\%).

A fim de identificar a gestão dos recursos dos respondentes, passa-se a analisar os dados obtidos a partira da Tabela 07 a 10. A Tabela 07 teve como finalidade, identificar no 
respondente qual sua percepção em relação ao planejamento a partir de anotações e controles individuais.

Tabela 07: Melhor opção que define o controle de seus gastos

\begin{tabular}{lcc} 
Tabela 07: Melhor opção que define o controle de seus gastos & Freq. & $\mathbf{\%}$ \\
\hline Anoto todas as despesas e sei dizer para onde está indo meu dinheiro. & 61 & 59 \\
\hline Gostaria de ter, mas não sei exatamente como fazer. & 2 & 2 \\
\hline Já tentei, mas acabo esquecendo de anotar as despesas. & 35 & 34 \\
\hline Nunca tentei fazer qualquer tipo de anotação dessa natureza. & 2 & 2 \\
\hline Não acho necessário fazer este tipo de controle. & 3 & 3 \\
\hline Total & $\mathbf{1 0 3}$ & $\mathbf{1 0 0}$ \\
\hline Legenda: & \\
\hline Freq.: Quantidade de respondentes &
\end{tabular}

Percebe-se pelos resultados apresentados na Tabela 07 que a maioria dos respondentes (61) anota todas as despesas sabendo para onde estão indo os recursos financeiros. Assim como identificado na literatura, a gestão e planejamento necessitam de persistência e dedicação, sendo evidenciado na pesquisa que $34 \%$ dos respondentes tentaram iniciar algum tipo de planejamento/gestão, mas que por algum motivo essa disciplina não foi totalmente ou corretamente seguida.

Para 2\% dos respondentes, gostariam de ter um planejamento, mas não sabem como fazer, ao passo que também para $2 \%$ nunca tentaram fazer qualquer tipo de anotação de seus gastos. O baixo percentual (3\%) acredita não ser necessário qualquer tipo de controle financeiro, denotando que o controle de gastos diminui o nível de endividamento das pessoas. Para Zerrenner (2007) as principais razões do endividamento podem ser atribuídas a incidentes pessoais/familiares $(21,6 \%)$, consumismo $(35,10 \%)$ e falta de controle (falta de planejamento e má administração do dinheiro) (43,10\%).

A Tabela 08 teve como principal objetivo identificar no respondente sua visão de longo prazo com foco em uma melhor qualidade de vida a partir de um do planejamento financeiro para reservas de aposentadoria.

Tabela 08: Reserva de recursos para aposentadoria

\begin{tabular}{lcc}
\hline & Freq. & $\mathbf{\%}$ \\
\hline Não me preocupei com isso ainda & 17 & 17 \\
\hline Pretendo ter apenas a aposentadoria do governo & 6 & 6 \\
\hline Faço um plano de previdência/poupança própria para aposentadoria & 47 & 46 \\
\hline Tenho planos de começar a poupar para isso & 32 & 31 \\
\hline Não vejo necessidade de poupar para minha aposentadoria & 1 & 1 \\
\hline Total & $\mathbf{1 0 3}$ & $\mathbf{1 0 0}$ \\
\hline Legenda: & \\
\hline Freq.: Quantidade de respondentes &
\end{tabular}


Nota-se pela Tabela 08 que quando questionados sobre a gestão financeira de longo prazo, ou seja, objetivando uma futura aposentadoria, $46 \%$ dos respondentes parecem estar preocupados com o futuro, afirmando estar com um plano de previdência ou poupança, garantindo assim o futuro com uma aposentadoria. Por outro lado, 31\% têm planos de começar a poupar para essa finalidade.

Para $17 \%$ dos respondentes a aposentadoria e a reserva de recursos ainda não faz parte de seus planos, assim como $1 \%$ dos respondentes consideram a poupança para aposentadoria desnecessária, ou seja, consomem os recursos sem indicação de planejamento futuro, como sendo uma necessidade de formarem uma reserva planejada. Já, que para $6 \%$ dos respondentes a reserva que pretendem dispor está relacionada a aposentadoria governamental, sendo que, contam que no futuro conseguirão atender suas necessidades financeiras com tal recurso.

A Tabela 09 buscou identificar nos respondentes sua preocupação, caso a qualquer momento fiquem desempregados, ou seja, buscou-se com essa pergunta, refletir sobre o planejamento econômico de curto prazo e a necessidade de poupar.

Tabela 09: Economia Financeira

\begin{tabular}{lcc|lcr}
\hline $\begin{array}{l}\text { Se a partir de hoje você ficasse sem emprego, por quanto } \\
\text { tempo sua reserva o sustentaria? }\end{array}$ & \multicolumn{4}{l}{$\begin{array}{l}\text { Sobre depósitos em poupança, com que frequência } \\
\text { realiza as aplicações? }\end{array}$} \\
\hline & Freq. & $\mathbf{\%}$ & & Freq. & $\mathbf{\%}$ \\
\hline Não tenho poupança & 18 & 17 & Sempre. & 18 & 17 \\
\hline Menos de seis meses & 43 & 42 & Frequentemente. & 24 & 23 \\
\hline De seis meses a um ano & 31 & 30 & Algumas Vezes. & 22 & 21 \\
\hline Mais do que um ano & 11 & 11 & Raramente. & 22 & 21 \\
\hline & & & Nunca. & 17 & 17 \\
\hline & $\mathbf{1 0 3}$ & $\mathbf{1 0 0}$ & Total & $\mathbf{1 0 3}$ & $\mathbf{1 0 0}$ \\
\hline
\end{tabular}

Legenda:

Freq.: Quantidade de respondentes

Fonte: Dados da pesquisa.

A pesquisa mostrou (Tabela 09 - Economia Financeira) que os respondentes possuem conhecimento de liquidez de ativos e que de certa forma estão preocupados com seu futuro, porém apesar de terem algum tipo de previdência/poupança, os recursos acumulados não são suficientes para muito tempo, ou seja, suas reservas suprem as necessidades de menos de seis meses $(42 \%)$ e de seis meses a um ano (30\%) em caso de desemprego. $17 \%$ dos respondentes não possuem poupança, assim como esses mesmos $17 \%$ nunca realizaram aplicações desse tipo. Já para $11 \%$ dos que responderam, suas reservas conseguem lhes manter (caso 
desempregados) por mais de um ano, sendo possivelmente a maioria dos $17 \%$ que sempre realizam depósitos em poupança.

Aliado a pergunta da Tabela 09 buscou-se identificar no respondente seu conhecimento sobre liquidez de ativos, a partir da pergunta: Se você tivesse recursos para investir, sem ter um prazo definido para resgatar, com qual das alternativas abaixo você mais se identificaria como aplicador? Os dados da pesquisa revelam que $41 \%$ preferem investimentos mais seguros como a poupança, ao contrário do identificado por Vieira et al. (2009) 11,5\%. Os respondentes apresentaram serem avessos a aplicações de elevado risco, a exemplo de ações (8\%), assim como identificado no estudo de Lucci et al.(2006), (15\%). Fundos de investimentos de médio risco é a terceira opção em investimentos (22\%), atrás de segunda opção (29\%), bens como carro, moto e imóvel. Para Vieira et al. (2009) 66,3\% preferem investir em fundos e $21 \%$ em bens como carro e imóveis.

A Tabela 10 buscou identificar o perfil dos respondentes quanto ao planejamento financeiro e controle dos gastos, tendo como foco relacionar o que se ganha com o que se gasta, equacionando da melhor forma as receitas e despesas.

Tabela 10: Perfil financeiro

Freq.

16

Possuo algumas dívidas das quais não consigo me livrar e/ou raramente consigo alguma sobra de recursos ao final do mês.

Meu salário praticamente empata com meus compromissos ou, com o pouco que sobra, eventualmente troco de carro ou poupa.

Tenho um plano de investimentos e procuro segui-lo objetivamente.

Total

Legenda:

Freq.: Quantidade de respondentes

Fonte: Dados da pesquisa.

Percebe-se pela Tabela 10 que a maioria dos respondentes $(51 \%)$ possui rendimentos que empatam com seus compromissos, sobrando poucos recursos para poupar ou investir em bens. 33\% dos respondentes possuem um plano de investimentos e procuram segui-lo objetivamente, por outro lado, $16 \%$ ainda possuem dívidas, das quais não estão conseguindo livrar-se financeiramente, sobrando com isso poucos recursos para investir no final do mês. Já 16\% não conseguem livrar-se das dívidas, semelhante ao identificado por Lucci et al. (2006) em que 12,8\% dos entrevistados não conseguem livrar-se das dívidas que possuem e $56,4 \%$ têm algum tipo de endividamento planejado, denotando possuírem consciência no comprar e financiar, gerindo de certa forma seus recursos, evitando assim um endividamento 
irresponsável. Comparado à Lizote, Simas e Lana (2012) os quais identificaram que a nota média dada pelos respondentes em relação as suas finanças pessoais foi de 7,20, os dados aqui apresentados podem ser considerados semelhantes, por não apresentarem unanimidade nas respostas.

\section{CONSIDERAÇÕES FINAIS}

O objetivo deste estudo foi analisar o nível de educação e gestão financeira dos funcionários de uma instituição de ensino superior do Meio Oeste Catarinense. Esta pesquisa se fundamentou por estudos já realizados sobre o tema, tendo como lacuna de pesquisa a investigação sobre o nível de educação e de gestão dos funcionários de uma Instituição de Ensino Superior.

A pesquisa mostrou que a maioria dos respondentes possuem especialização/MBA em alguma área do conhecimento, o que contribui para o conhecimento de suas finanças pessoais, que $44 \%$ não possuem dívidas elaborando sempre algum tipo de planejamento e $26 \%$ ao passo que possuem dívidas estão em condições de pagá-las, tomando o cuidado de anotar quando e como pagar. Percebeu-se ainda que o percentual das despesas está concentrado nos gastos com moradia educação e transporte, num total de quase $40 \%$ dos recursos financeiros.

Sobre a educação e gestão financeira dos pesquisados, o estudo mostrou que possuem um adequado entendimento de liquidez e de juros financeiros e, que a maioria, possui algum tipo de previdência ou outra forma de investimento de baixo risco na tentativa de garantir de seu futuro. Porém, os valores acumulados são suficientes apenas para, em caso de desemprego suprir as necessidades até um ano, semelhante aos achados de Lucci et al. (2006) e de Vieira et al. (2009). O estudo mostrou ainda que o grau de escolaridade, assim como nos estudos de Lucci et al. (2006) e Vieira et al. (2009) faz a diferença na gestão das finanças pessoais e com base, na literatura, para se obter sucesso no planejamento financeiro é necessário muita dedicação e persistência, como mostra nossos resultados em que 59\% dos pesquisados anotam todas as despesas e 34\% já tentaram mas acabam esquecendo de anotarem algumas despesas.

Conclui-se pela pesquisa, que os respondentes possuem um adequado nível de conhecimento e de gestão de seus recursos financeiros, ou seja, a maioria busca conhecimentos a partir da família tendo como principal fonte de financiamento a própria renda familiar. A maioria possui um nível de conhecimento de liquidez, juros e aplicações, estando preocupados não só com o presente, mas com o futuro (aposentadoria). A maioria dos 
respondentes entende a importância da gestão dos recursos (59\%) possuindo algum tipo de anotações de seus gastos.

O estudo contribui para a pesquisa em finanças pessoais, mostrando que o nível de escolaridade tem relação com a uma maior educação financeira, ajudando nas decisões diárias a serem tomadas. Nesse sentido a pergunta de pesquisa: qual o nível de educação e gestão financeira dos funcionários de uma instituição de ensino superior do Meio Oeste Catarinenses?, foi respondida a partir dos dados encontrados em que observou-se que os respondentes possuem conhecimento sobre finanças, sendo demonstrado pelo entendimento de liquidez, juros e aplicação financeira, assim como um bom gerenciamento de seus recursos em que a maioria possui certo volume de economia de recursos, indicando que há um gerenciamento dos gastos e uma perspectiva futura de manter ou até mesmo aumentar sua qualidade de vida.

Como limitações do estudo, não se pode generalizar os dados aqui obtidos às demais instituições de ensino superior da Região ou do País, haja vista, uma pequena amostra de pesquisados e por outro lado por se tratar de respostas espontâneas, há de certa forma um grau de erro e subjetividade nas respostas.

Sugere-se para futuras pesquisas, a realização em outros ambientes, como mais universidades, órgãos públicos e empresas, pois são bastante reduzidas as pesquisas que indagam funcionários de empresas industriais e comerciais envolvendo a temática de finanças pessoais. Nesse sentido sugere-se ainda a aplicação simulada de decisões financeiras (investimentos e financiamentos) aplicando a teoria das finanças comportamentais. 


\section{REFERÊNCIAS}

ASSUNÇÃO, A.B.A. Comportamento dos contadores diante de uma visão otimista ou pessimista de um ambiente econômico simulado. 2011, 76 f. (Dissertação de Mestrado) Universidade Federal de Brasília, Brasília, 2011

BARBER, B., ODEAN, T. Online investors: do the slow die first? Review of Financial Studies, v.15, p. 455-487, 2002.

BERNHEIM, D.B.; GARRET, D. M.; MAKI, D.M. Education and saving: the long term effects of high school financial curriculum mandates. National Bureau of Economic Research, Cambridge, n. 6085, jul./1997. Disponível em: <http://www.nber.org/papers/w6085.pdf>. Acesso em: 01 ago. 2013.

CAMARGO, C. Planejamento financeiro pessoal e decisões financeiras organizacionais: relações e implicações sobre o desempenho organizacional no varejo. 2007. $100 \mathrm{f}$. Dissertação (Mestrado em Administração). Centro de Pesquisa e Pós-Graduação em Administração, Universidade Federal do Paraná, Curitiba, 2007.

CARDUCCI, B.; WONG, A. Type a and risk taking in everyday money matters. Journal of Business and Psychology, v. 12, n. 3, p. 355-359, 1998.

CHEN, H.; VOLPE, R. An Analysis of Personal Financial Literacy among College Students. Financial Services Review. v. 7, n.2, p.107, 1998.

CHEN, H.; VOLPE, R. Gender Differences in Personal Financial Literacy among College Students. Financial Services Review. v. 11, n. 3, p.289, 2002.

CLAUDINO, L.P.; NUNES, M.B.; SILVA, F.C. Finanças pessoais: um estudo de caso com servidores públicos. In: SEMINÁRIO EM ADMINISTRAÇÃO - FEA-USP. 12., São Paulo, 2009. Anais eletrônicos... São Paulo, USP, 2009. Disponível em: <http://www.ead.fea.usp.br/semead/12semead/resultado/trabalhosPDF/724.pdf >. Acesso em: 23 de ago. 2013.

COLLIS, J.; HUSSEY, R. Pesquisa em Administração - Um guia prático para alunos de graduação e pós graduação. 2 ed. Bookman. Porto Alegre. 2005.

DOLVIN, S.; TEMPLETON,W.K. Financial education and asset allocation. Financial Services Review. v.15, p. 133-149, 2006.

FRANKENBERG, L. Seu Futuro Financeiro: você é o maior responsável. São Paulo: Campus, 1999.

GITMAN, L. J. Princípios de Administração Financeira. 7ª ed. São Paulo: Harbra, 1997.

INSTITUTO BRASILEIRO DE GEOGRAFIA E ESTATÍSTICA - IBGE. Pesquisa de Orçamentos Familiares (2008-2009). Disponível em: <http://www.ibge.gov.br/home/estatistica/populacao/condicaodevida/pof/2008_2009/POFpub licacao.pdf $>$. Acesso em 09 nov. 2013. 
KAHNEMAN, D. e TVERSKY, A. Prospect Theory: an analysis of decision under risk.Econometrica, Menasha: Econometric Society, v. 47, n. 2, p. 263-291, mar. 1979.

LIMA, M.V. Um estudo sobre as finanças comportamentais. Revista de Administração Eletrônica - RAE, v. 2, n.1, p. 1-19, jan./jun. 2003.

LUNT, P.K.; LIVINGSTONE, S.M. Psychological, social and economic determinants of saving: Comparing recurrent and total savings. Journal of Economic Psychology 12, 1991, p. 621-641.

LUSARDI, A., MITCHELL, O. S. Financial Literacy and Planning: Implications for Retirement Wellbeing. National Bureau of Economic Research. Paper n. 17078. Mai/2011

MANTON, E.J. et al. What College Freshmen Admit To Not Knowing About Personal Finance. Journal of College Teaching \& Learning, v. 3 n. 1, Jan. 2006.

MANKIW, N. G. Introdução a economia: princípios de micro e macroeconomia. Rio de Janeiro: Campus, 1999.

NAVARO, C. Vamos falar de Dinheiro: uma conversa franca sobre atitude, comportamento, planejamento financeiro e sucesso nos investimentos. São Paulo. Novatec, 2009.

PIMENTA, D.P.; BORSATO, J.M.L.S.; RIBEIRO, K.C.S. um estudo sobre a influência das características sociodemográficas e do excesso de confiança nas decisões dos investidores, analistas e profissionais de investimento à luz das finanças comportamentais. Revista de Gestão. v. 19, n. 2, p. 261-278, abr./jun. 2012

PINHEIRO, R.P. Educação financeira e previdenciária, a nova fronteira dos fundos de pensão. Artigo Publicado no Livro. Fundos de Pensão e Mercado de Capitais. Instituto San Tiago Dantas de Direito e Economia e Editora Peixoto Neto. São Paulo. set/2008.

ROGERS, P.; SECURATO, J.R; RIBEIRO, K.C. S; ARAÙJO. S.R. Finanças Comportamentais no Brasil: Em Estudo Comparativo. Revista de Economia e Administração, v. 6, n. 1, p. 49-68, jan./mar. 2007.

ROSS, S.A.; WERTERFIELD, R.W.; JAFFE, J.F. Administração Financeira. Tradução de Antonio Zoratto Sanvicente. São Paulo: Atlas, 2002.

SERRA, et al. Vieses comportamentais na decisão de investimentos: um estudo empírico. Revista de Finanças Aplicadas, v.1, p.1-23, set/2010.

SOUSA, A. F. de.; TORRALVO C. F. A gestão dos próprios recursos e a importância do planejamento financeiro pessoal. In: SEMINÁRIO EM ADMINISTRAÇÃO - FEA-USP . 7 ., São Paulo, 2003. Anais eletrônicos... São Paulo, USP, 2003. Disponível.em:.<http://www.ead.fea.usp.br/semead/7semead/paginas/artigos\%20recebidos/Fi nan\%E7as/FIN01-_A_gest\%E3o_dos_pr\%F3prios_recursos.PDF> Acesso em: 02 set. 2013.

TENNYSON, S.,NGUYEN, C. State Curriculum Mandates and Student Knowledge of Personal Finance. The Journal of Consumer Affairs, v. 35, n. 21, p. 241-262, 2001. 
TVERSKY, A.; KAHNEMAN, D. Judgment under uncertainty: heuristics and biases. Science, v.185, n. 4157, p. 1124-1131, 1974.

VIEIRA et al. Educação Financeira e Decisões de Consumo, Investimento e Poupança: Uma Análise dos Alunos de uma Universidade Pública Do Paraná. In: SEMINÁRIO EM ADMINISTRAÇÃO - FEA-USP. 12., São Paulo, 2009. Anais eletrônicos... São Paulo, USP, 2009. Disponível em:

http://www.ead.fea.usp.br/semead/12semead/resultado/trabalhosPDF/341.pdf>. Acesso em: 31 ago. 2013.

VITT, Lois A. Consumers' Financial Decisions and the Psychology of Values. Journal of Financial Service Professionals, Nov/2004.ZERRENNER, S.A. Estudo Sobre as razões para a população de baixa renda. 2007. $57 \mathrm{f}$. Dissertação (Mestre em Ciências Administrativas) - Universidade de São Paulo, São Paulo, 2007. 